\title{
O fenômeno do bullying homofóbico nas instituições de ensino: o direito à igualdade sexual e o princípio da dignidade da pessoa humana
}

\author{
Graziela Raupp PEREIRA ${ }^{1}$ \\ Cristina Monteggia VARELA ${ }^{2}$ \\ Guilherme Pereira SILVEIRA ${ }^{3}$
}

\section{Introdução}

Sendo a violência uma das grandes questôes sociais a serem solucionadas pela humanidade, traz-nos um olhar sobre a compreensão deste fenômeno praticada contra crianças e adolescentes, proporcionando-nos um mergulho na identificação de fatores que movem esta violência social. (SILVEIRA et al., 2011, p.347).

A discriminação por identidade de gênero, orientação sexual, geracional, etnia-racial, classe social, religião, deficiências mentais ou físicas, não é uma novidade nas instituições de ensino e com o passar do tempo percebe-se que

1 Pós-doutorado em Educação. Pesquisadora do Grupo de Pesquisa Educação Sexual e Formação de Professores (EDUSEX CNPq) e do Laboratório de Educação Sexual (LabEdusex). UDESC - Universidade do Estado de Santa Catarina. Centro de Educação a Distância. Florianópolis - SC - Brasil. 88.035-901 - raupp.graziela@ gmail.com

2 Doutoranda em Educação. Pesquisadora do Grupo de Pesquisa Gênero e Diversidade na Escola (GESE). FURG - Universidade Federal de Rio Grande - Pós-Graduação em Educação em Ciências. Rio Grande - RS - Brasil. 96203-900 - cmonteggiavarela@ gmail.com

3 Especialista e Bacharel em Direito. Assistente de Promotoria do Ministério Público de Santa Catarina. Florianópolis - SC - Brasil.88015-904-gpereirasilveira@ gmail.com 
O fenômeno do bullying homofóbico nas instituiçóes de ensino: o direito à igualdade sexual e o princípio da dignidade da pessoa humana

essas violências têm se transformado em um problema pernicioso. Para Pereira (2012, p. 204),

É certo que a sexualidade humana figura como um dos temas mais inquietantes e, quase sempre, mais recusados na ação prática do professor. Entretanto, cada vez mais a escola tem sido convocada a enfrentar as transformaçóes das práticas sexuais contemporâneas, uma vez que seus efeitos se fazem alardear no cotidiano escolar.

Nesse contexto, a prática do bullying homofóbico ultrapassa as barreiras dos direitos humanos, ocasionando inúmeros malefícios para a educação e o desenvolver de uma sociedade. Este artigo pretende discutir as consequências que o fenômeno do bullying homofóbico traz para a humanidade na vivência plena de seus Direitos Sexuais entendidos como Direitos Humanos Universais e Fundamentais, mais especificamente ao princípio da dignidade da pessoa humana, um tema ainda pouco difundido, embora frequente, muitas vezes esquecido pela comunidade educacional.

Não se tem a pretensão de esgotar a temática proposta, mas trazer reflexốes sobre este dilema, por se perceber as sérias consequências que tal problemática acarreta para a educaçáo, e consequentemente para a sociedade contemporânea, que encontra imensas dificuldades em combatê-lo, mesmo que as condutas exercidas no bullying sejam de extrema crueldade e firam intensamente os direitos sexuais, principalmente em sua própria condição de ser humano. Por isso a inquietação em proporcionar um pouco mais de reflexão sobre esta questáo, trazendo o enfoque principal de estudo para o direito à igualdade sexual e o princípio da dignidade da pessoa humana frente à incidência do bullying homofóbico.

Ser vítima dessa violência não é condição difícil nos dias de hoje, pelo contrário, tem-se tornado prática costumeira na vida de muitos estudantes e, por diversas vezes, este fenômeno náo tem sido identificado como uma violência social. Tal ponto precisa ser profundamente discutido, tendo em vista de que o bullying homofóbico não é identificado como violência, em muitos casos por professores/as, gestores/as e equipe escolar, que considera o tema ainda muito delicado de ser abordado, optando pelo silêncio. De acordo com Antonio et al. (2012, p. 20) "[...] o bullying homofóbico pode tornar-se mais grave relativamente ao bullying em geral por ser menos visível e menos credibilizado do que as outras formas de bullying, inclusive pelos/as próprios/as professores/as."

Para o desenvolvimento dessa discussão, optou-se pelo método de abordagem dedutivo, partindo-se de premissas gerais já consagradas, as quais servem de alicerce para se alcançar os conhecimentos aqui pretendidos, através da pesquisa bibliográfica, consultando declaraçôes, legislaçôes, doutrinas e 
jurisprudências, onde foram estudados os aspectos gerais do fenômeno do bullying homofóbico, trazendo-se à reflexão o conceito, as especificidades e os pressupostos dessa violência visando compreender de forma mais contundente a incidência desse fenômeno na condição humana, discutindo a importância do abrangente significado de direito e dignidade, traçando o aporte teórico e as consideraçóes do direito à igualdade sexual e do princípio da dignidade da pessoa humana frente à prática do fenômeno do bullying homofóbico, enfatizando sua repercussão e suas consequências.

\section{Bullying Homofóbico}

O bullying é uma palavra originária do inglês - sem tradução equivalente no Brasil - cuja denominação reflete um conjunto de comportamentos antissociais, agressivos e reiterados com o intuito de maltratar, oprimir e humilhar determinada pessoa ou um grupo de pessoas. Segundo os autores Fante e Pedra (2008, p. 33), o termo bullying é utilizado para expressar "o desejo consciente e deliberado de maltratar uma pessoa e colocá-la sob tensão".

O fenômeno do bullying não é novo em nosso cotidiano. Entretanto, foi no início dos anos de 1970 que este problema passou a ser enxergado com maior importância pelos pesquisadores da comunidade científica internacional, em especial pelo professor norueguês Dan Olweus mencionado na obra de Teixeira (2011). Nas últimas décadas as pesquisas sobre o tema cresceram muito, mas náo se pode dizer o mesmo dos estudos específicos a respeito do bullying homofóbico, que ainda é pouco estudado e discutido no mundo da educaçã.

Com o decorrer dos estudos realizados, percebeu-se que o fenômeno do bullying não é uma violência social exclusiva de um determinado país, de determinadas escolas, mas de um problema de abrangência global presente em culturas do mundo todo (LOPES NETO, 2011).

De acordo com A. Silva (2010, p. 21):

Se recorrermos ao dicionário, encontraremos as seguintes traduçóes para a palavra bully: indivíduo valentão, tirano, mandão, brigão. Já a expressão bullying corresponde a um conjunto de atitudes de violência física e/ou psicológica, de caráter intencional e repetitivo, praticado por um bully (agressor) contra uma ou mais vítimas que se encontram impossibilitadas de se defender. Seja por uma questão circunstancial ou por uma desigualdade subjetiva de poder, por trás dessas açóes sempre há um bully que domina a maioria dos alunos de uma turma e 'proíbe' qualquer atitude solidária em relação ao agredido.

Dito isso, pode-se perceber que o bullying não é uma atitude cruel eventual. É a agressão intencional e reiterada, voltada a determinado/s indivíduo/s, 
O fenômeno do bullying homofóbico nas instituiçóes de ensino: o direito à igualdade sexual e o princípio da dignidade da pessoa humana

perpetrada por uma ou mais pessoas, cuja finalidade é a de se alcançar domínio sobre o outro, por meio do sofrimento físico elou psicológico (MIDDELTONMOZ; ZAWADSKI, 2007), sendo importante ressaltar que para configurar o bullying é imprescindível a existência de um contexto social, no qual as pessoas estejam se relacionando umas com as outras, de forma contínua e duradoura (LOPES NETO, 2011).

Consideramos importante ressaltar que compreendemos o conceito de homofobia como sendo um conjunto de sentimentos e emoçóes negativas direcionadas a pessoas com orientação sexual diferentes da norma heterossexual. Assim a homofobia compreende as reações de aversão, ódio, medo, entre outros, contra pessoas homossexuais ou assim idendificadas.

De acordo com Junqueira (2015, p.4):

[...] seriam indícios (ou "sintomas") de homofobia o ato de se evitarem homossexuais e situaçôes associáveis ao universo homossexual, bem como a repulsa às relaçóes afetivas e sexuais entre pessoas do mesmo sexo. Essa repulsa, por sua vez, poderia se traduzir em um ódio generalizado (e, de novo, "patológico") às pessoas homossexuais ou vistas como homossexuais.

Dessa forma, as instituiçóes de ensino estão permeadas pelo fenômeno do bullying homofóbico. Este pode ser expresso de diversas formas como por meio das agressóes verbais e/ou físicas. Dentre as mais comuns estão, por exemplo, falar mal, xingar, ameaçar, intimidar, gritar, bater, chutar, empurrar, derrubar, ferir, perseguir, amedrontar, apelidar, discriminar, humilhar, tiranizar, excluir, dominar, difamar, assediar, abusar, violentar, hostilizar, ofender, furtar e quebrar objetos pessoais de pessoas homossexuais ou entendidas como tal (TEIXEIRA, 2011, p. 26-27).

Para O'Higgins-Norman, citado por Antônio et al. (2012, p. 20) podemos caracterizar a prática do bullying homofóbico em duas vertentes:

(a) o bullying subjacente ao caráter hetero-normativo do ambiente escolar, relacionado com as expectativas de papel de gênero independentemente da orientação sexual da vítima, nomeadamente ao nível do policiamento dos comportamentos considerados representativos dos gêneros feminino e masculino; e (b) o bullying que tem por base comportamentos discriminatórios e persecutórios contra pessoas LGBT ${ }^{4}$.

Nesse contexto, a perspectiva de compreensão por anos reafirmada no modelo heteronormativo, consolidou um espaço de repúdio ao diverso, caracterizando a prática do bullying homofóbico em ambas as suas vertentes

4 Sigla para Lésbicas, Gay, Bissexuais, Travestis e Transexuais. 
como forma de autoafirmação dos indivíduos por meio da violência, tendo como base os estereótipos de gênero para consolidar uma prática, cada vez mais agressiva e ainda pouco reconhecida. Em verdade, o fenômeno do bullying homofóbico é uma problemática perniciosa que infringe as barreiras do bem estar, que pode ocasionar - e normalmente ocasiona - com sua incidência diversos malefícios para o desenvolvimento de uma sociedade mais digna, justa e igualitária.

As ações perpetradas com a prática do bullying homofóbico, como já observado, são cruéis e destrutivas, sendo que nas instituições de ensino é reconhecido, especificamente, nas violências sofridas por alunos e alunas homossexuais, bissexuais, transexuais e travestis. Ocorrem frequentemente em instituiçóes educacionais do mundo todo, porém em grande parte, percebe-se que não são identificadas como uma violência social. Indubitavelmente, ser vítima do fenômeno do bullying homofóbico não é, atualmente, uma situação rara, pelo contrário, tem-se tornado um problema diário na educação.

Por tais razões, alguns estudiosos desta temática como Fante e Pedra (2008), têm adotado os ensinamentos do pesquisador nórdico Dan Olweu, o qual fixou critérios objetivos para constatar se o comportamento empregado trata-se ou não do fenômeno do bullying. Com estes critérios, é possível diferenciar o que é violência e o que são brincadeiras inocentes da idade. De acordo com Dan Olweus, os critérios estabelecidos foram: açóes reiteradas em desfavor da mesma pessoa num longo período de tempo; desproporção de poder entre agressor e agredido; e ausência de causa ou motivo aparente que expliquem as agressóes (FANTE; PEDRA, 2008).

Para A. Silva (2010), o acobardar, a opressão e o abuso de poder são algumas das variadas formas utilizadas pelos agressores do bullying para impor sua força e arbítrio e, então, manter suas "presas" sob controle.

Apesar dos seus desdobramentos e variaçóes, o fenômeno do bullying pode se dividir em duas formas de classificação: bullying direto e bullying indireto, pois sua definição depende da maneira em que as condutas (agressivas) são impostas aos vitimados (TEIXEIRA, 2011). A primeira é aquela praticada abertamente e, portanto, mais fácil de ser reconhecida, uma vez que o agressor age diretamente contra a vítima, com intimidações, violência, hostilização etc. Já a segunda ocorre discretamente, isto é, prescinde da presença física da vítima para que se perfectibilizem, é o caso das difamaçóes, ameaças e fofocas. Entretanto, verificase que não é incomum as vítimas do bullying sofrerem tão somente uma conduta violenta. Na maioria das vezes, os atos agressivos dos praticantes do bullying costumam vir conjuntamente, tanto na forma direta, como na forma indireta (SILVA, A., 2010). 
O fenômeno do bullying homofóbico nas instituiçóes de ensino: o direito à igualdade sexual e o princípio da dignidade da pessoa humana

Temos, ainda, um novo meio de prática do bullying atualmente, o cyberbullying ${ }^{5}$, prática do bullying por meio das nídias sociais e demais meios de comunicação e informação. Mesmo não sendo foco desse artigo, se faz necessário o alerta, por cada vez mais ter sua prática disseminada nas instituiçóes de ensino, aumentando muito o número de vítimas dos crimes de homofobia, em nossa contemporaneidade.

Em face do exposto, pode-se dizer que o fenômeno do bullying homofóbico é uma rejeição a "anormalidade", ou seja, de privar aqueles que resistem a se enquadrarem a heteronormatividade, conceito criado pelo pesquisador Michael Warner (1993) para descrever a forma que toma a sexualidade heterossexual como norma universal e os discursos que descrevem a situação homossexual como desviante, errada, promíscua. Nessa perspectiva, a prática do bullying homofóbico pode acarretar consequências cruéis e devastadoras na educação, às instituiçóes educacionais, principalmente às vítimas dessa violência.

Segundo Teixeira (2011), pesquisas científicas já realizadas evidenciam que, em razão da incidência do bullying - condutas agressivas intencionais e reiteradas - os danos ocasionados por este fenômeno podem perdurar por toda a vida. É importante assinalar que dentre os danos decorrentes deste comportamento, é possível vislumbrar o estresse, como responsável por aproximadamente $80 \%$ do rebaixamento da resistência imunológica e dos sintomas psicossomáticos variados (CALHAU, 2010). Posto isso, verifica-se que o fenômeno do bullying homofóbico pode ocasionar inúmeros sintomas no desenvolver sadio de crianças, adolescentes, jovens e adultos, como depressão, medo, insônia, ansiedade, fobia, ausência de estímulos, vingança, entre outros. Salienta Calhau (2010) que, em casos mais graves, os alvos do bullying podem cometer até mesmo o suicídio ou reproduzir os atos de violência contra si perpetrados.

Geralmente, as vítimas do bullying homofóbicos são pessoas mais propensas a apresentar baixa autoestima e quadros depressivos e, citando Louro (1997, p. 67):

Ao não falar a respeito deles e delas, talvez se pretenda eliminá-los, ou, pelo menos, se pretenda evitar que os alunos e as alunas 'normais' os/as conheçam e possam desejá-los/as. Aqui, o silenciamento - a ausência da fala - aparece como uma espécie de garantia da 'norma'.

Nesse diapasão, pode-se afirmar que o comportamento depressivo, a fobia, a ansiedade e o medo que muitas vítimas dos ataques praticados pelos agressores do

5 Compreende-se por cyberbulling a prática de violência praticada no espaço virtual, por meio das mídias sociais. 
bullying homofóbico sofrem contribui para a evasão nos contextos educacionais, uma vez que estes se entendem fora do padrão considerado "normal", a norma heterossexual, ao expressarem suas identidades sexuais e de gênero.

Em grande parte, são jovens introspectivos, frágeis, acanhados e/ou possuem peculiaridades que os tornam "distintos" dos outros indivíduos. Já os autores do bullying homofóbico, os bullies, são pessoas com características específicas, dentre elas: pouco afetivos agressivos e empáticos (SILVA, A., 2010). São indivíduos autoconfiantes que carecem de poder de domínio sobre o outro, geralmente oriundos da força física ou com imensa habilidade emocional (SILVA, A., 2010). Para estes (agressores), as consequências se relacionam com o uso do álcool, drogas ilícitas, envolvimento com a criminalidade (TEIXEIRA, 2011).

Por todo o exposto, o fenômeno do bullying homofóbico não pode ser visto como uma atitude inocente, sem intenção de gerar dano, ou ser considerado uma violência praticada por alguns. Explica Lopes Neto (2011) que este fenômeno é um problema social, derivado de questóes socioculturais, familiares e até mesmo do próprio ambiente em que é praticado. É uma problemática existente no mundo inteiro, presente nas variadas classes sociais e instituiçóes de ensino.

\section{Direito a Igualdade Sexual e a Dignidade da Pessoa Humana}

A igualdade, para alguns/mas doutrinadores/as, é a principal garantia constitucional assegurada aos seres humanos - e, de fato, ela é de extrema importância. Todavia, há quem entenda que o principal direito fundamental constitucionalmente protegido é o da dignidade da pessoa humana.

Consagrada no inciso III, do art. 1º, da Constituição Federal de 1988, como um dos fundamentos da República Federativa do Brasil, a dignidade da pessoa humana representa a proteçâo dos direitos individuais. É ela, a dignidade, que dá o norte, o sentido ao intérprete.

De origem etimológica, proveniente da expressão latina dignitas, a palavra dignidade representa o prestígio, a estima, a consideração, a respeitabilidade. Em outras palavras, é o atributo ou valor de tudo aquilo "que é digno e merece respeito ou reverência”. (ALVES, 2001, p. 109).

Conforme Sarlet (2006), o conceito de dignidade é ainda um problema, principalmente por se tratar de um atributo intrínseco a todo e qualquer ser humano. Logo, para buscar a definição do abrangente significado de dignidade, faz-se necessário levar em consideração todas as violaçóes até hoje ocorridas, para que contra elas se possa guerrear. Com essa construção histórica, é que se pode afirmar que a dignidade já nasceu com o homem e que a ele é inerente (SARLET, 2006).

É sabido que a pessoa humana é o elemento central dos direitos humanos. É a pessoa humana o antecedente indispensável, do qual derivam todos os direitos 
O fenômeno do bullying homofóbico nas instituiçóes de ensino: o direito à igualdade sexual e o princípio da dignidade da pessoa humana

dos homens. Portanto, estes direitos subsistem em virtude dela e se fundamentam na sua natureza (OLIVEIRA, 2000).

No entanto, é preciso que os seres humanos também tenham visibilidade nos contextos sociais dos quais façam parte, e não somente na sua individualidade. Isso porque, embora nasçam com integridade física e psíquica, é o convívio social, a coletividade como um todo, que o faz alcançar o respeito e a consideraçáo dos demais membros de uma sociedade. E esses atributos pela dignidade se iniciam a partir de pequenos gestos do cotidiano, os quais nos fazem almejar um mundo mais igualitário e humano.

Segundo J. Afonso da Silva (2012, p.105), a dignidade da pessoa humana pode ser compreendida como:

[...] um valor supremo que atrai o conteúdo de todos os direitos fundamentais do homem, desde o direito à vida. "Concebido como referência constitucional unificadora de todos os direitos fundamentais [observam Gomes Canotilho e Vital Moreira], o conceito de dignidade da pessoa humana obriga a uma densificaçáo valorativa que tenha em conta o seu amplo sentido normativoconstitucional e não uma qualquer ideia apriorística do homem, não podendo reduzir-se o sentido da dignidade da pessoa humana à defesa dos direitos pessoais tradicionais, esquecendo-a nos casos de direitos sociais, ou invocá-la para construir 'teoria do núcleo da personalidade' individual, ignorando-a quando se trate de garantir as bases da existência humana".

Moraes (2006, p. 16) define a dignidade como:

[...] um valor espiritual e moral inerente à pessoa, que se manifesta singularmente na autodeterminação consciente e responsável da própria vida e que traz consigo a pretensão ao respeito por parte das demais pessoas, constituindo-se um mínimo invulnerável que todo estatuto jurídico deve assegurar, de modo que, somente excepcionalmente, possam ser feitas limitações ao exercício dos direitos fundamentais, mas sempre sem menosprezar a necessária estima que merecem todas as pessoas enquanto seres humanos.

De fato, a noção de dignidade humana ainda possui uma definição vaga e imprecisa, e embora não se possa determinar com eficácia um conceito contundente, a dignidade passou a ser considerada como um valor supremo que caracteriza o homem - um atributo pessoal - e, portanto, classificada como bem irrenunciável e inalienável (SARLET, 2006).

Sendo assim, pode-se afirmar que o princípio da dignidade da pessoa humana é a imposição de deveres e direitos, para que as pessoas possam exteriorizar comportamentos tendentes a proteger à condição humana. É uma 
imposição que estabelece ao Poder Público o dever de velar, garantir, proteger e promover a vida com dignidade.

Em consonância com a tendência mundial, a Constituiçáo Brasileira de 1988 consagrou a dignidade da pessoa humana como princípio fundamental do Estado Democrático de Direito, exigindo por parte dos órgãos estatais tanto uma prestação positiva quanto negativa.

Neste sentido, oportuno se faz acrescentar os ensinamentos do doutrinador Sarlet acerca dos limites do Estado frente ao princípio da dignidade da pessoa humana, como exposto a seguir:

[...] o princípio da dignidade da pessoa humana impóe limites à atuação estatal, objetivando impedir que o poder público venha a violar a dignidade pessoal, mas também implica (numa perspectiva que se poderia designar de programática ou impositiva, mas nem por isso destituída de plena eficácia) que o Estado deverá ter como meta permanente, proteçáo, promoçáo e realizaçáo concreta de uma vida com dignidade para todos, podendo-se sustentar, na esteira da luminosa proposta de Clèmerson Clève, a necessidade de uma política da dignidade da pessoa humana e dos direitos fundamentais. (SARLET, 2006, p. 110).

Dessa forma, como tarefa imposta ao Poder Público, a dignidade da pessoa humana necessita que este direcione seus atos no sentido de proteger e zelar pela dignidade já existente, bem como de criar condiçóes para promovê-la. Posto isso, não pairam dúvidas de que todos [Estado e sociedade] estão ligados ao princípio da dignidade da pessoa humana, e que possuem os mesmos deveres de guarida, respeito e promoção.

Aliás, como se observa, a dignidade humana existe e pode ser identificada, quando vislumbradas situaçōes em que ela foi infringida, violada. No entanto, embora prescinda de uma definição própria, o conteúdo em dignidade da pessoa humana integra a base primordial dos direitos fundamentais. O legislador de 88 - embora náo tenha elencado a dignidade da pessoa humana como um direito fundamental - elevou a dignidade humana em nível de princípio fundamental, tornando-a elemento essencial para a interpretação e criação das normas e, sobretudo, promovendo a guarida dos direitos individuais contra atos abusivos e/ ou restritivos.

Se assim o é, pode-se afirmar que sempre que houver uma violação pela integridade física e/ou moral, ou pela vida propriamente dita, deixando de se observar e respeitar as condiçóes mínimas existências para se construir uma vida justa e igualitária, estará se legitimando as injustiças.

Portanto, é preciso uma adequação do Poder Público juntamente com a sociedade, objetivando o bem comum, seja por meio de leis e/ou através de 
O fenômeno do bullying homofóbico nas instituiçóes de ensino: o direito à igualdade sexual e o princípio da dignidade da pessoa humana

políticas públicas, mas que em qualquer dos casos seja garantido, em todos os níveis (jurídicos, educacionais, culturais, econômicos e sociais), a dignidade da pessoa humana como o bem maior.

Dito isso, pode-se concluir que a dignidade da pessoa humana, de fato, encontra-se no epicentro do ordenamento jurídico brasileiro, e que é um direito fundamental constitucionalmente garantido a todo e qualquer ser humano, uma vez que representa a valorização da pessoa humana, tornando-se o embasamento estrutural do Estado Democrático de Direito.

\section{O bullying homofóbico, suas consequências e a necessidade de formação}

O processo de formação do ser humano encontra-se intimamente ligado ao pleno amadurecimento e desenvolvimento físico e mental, que decorre principalmente nos períodos da infância e da juventude. São essas experiências que fornecem efetivamente a construção de sua identidade, caráter e índole, características primordiais para a formação do ser humano em meio à coletividade (LOPES NETO, 2011).

Dito isso, bullying homofóbico, de fato, é uma problemática de abrangência global que pode acarretar - e geralmente acarreta - deficiências na habilidade do ser humano, principalmente na sua formação acadêmica e social.

Ao se perceber a ocorrência do bullying homofóbico, providências necessitam ser tomadas para que esse tipo de comportamento - cruel e destrutivo - seja cessado. Contudo, e não são poucos os casos, em que os vitimados do bullying homofóbico dão ciência às instituições de ensino, mas sem sucesso. Outras vezes, a própria instituição de ensino está ciente do problema, mas não consegue solucioná-lo, fazendo com que estudantes/vítimas se afastem do ambiente educacional.

Em verdade, o fenômeno do bullying homofóbico é uma violência que fere os preceitos fundamentais da Constituição Federativa do Brasil, em especial o direito a igualdade e a não discriminação e a dignidade da pessoa humana (WAS, 1999).

Como já observado, o princípio da dignidade da pessoa humana adveio para assegurar/garantir direitos básicos e essenciais a todas as pessoas, bem como promover a participação ao contexto educacional/social. Logo, constata-se que a dignidade é o próprio atributo intrínseco do ser humano. Do desdobramento desse princípio, constata-se que ninguém dele pode se abster. Isso porque, a guarida e a defesa da dignidade da pessoa humana, na esfera jurídica, alcançaram suma relevância no final deste século, consequência de pesquisas científicas e tecnológicas testadas na humanidade, que acabaram por elevar de maneira acentuada riscos e danos no dia a dia dos seres humanos (ALVES, 2001). 
O fenômeno do bullying homofóbico, de fato, é uma afronta ao princípio da dignidade da pessoa humana, na medida em que se caracteriza como um comportamento cruel, desumano e intolerável, causador de imenso sofrimento aos vitimados da sua prática. É uma violência que se utiliza da vítima - como mero instrumento - para se obter uma satisfação pessoal, ou seja, a de causar dor, ódio e humilhação a outrem.

Se assim o é, ao Poder Público, a sociedade e a educação cabem, através de açóes positivas e negativas, repelirem qualquer forma de discriminação e priorizar, essencialmente, a autodeterminação em vista de comportamentos destrutivos e arbitrários.

Ademais, sabe-se que

[...] os sistemas educativos prevêem abordagem nos princípios da educação para a cidadania, para a cultura de paz, para promoçáo da igualdade de oportunidades, eliminação de todas as formas de discriminação, tolerância, respeito à diferença e à diversidade e justiça social. (SILVEIRA et al., 2011, p.352).

Nessa esteira, a Declaração Universal da Organização das Nações Unidas ONU (1998), em seu art. 10, estabelece que: "[...] todos os seres humanos nascem livres e iguais em dignidade e direitos. Dotados de razão e consciência, devem agir uns para com os outros em espírito e fraternidade."

No mesmo sentido, a Constituição Federal de $88 \mathrm{em}$ seu art. 5º, inciso X, acrescenta:

todos são iguais perante a lei, sem distinção de qualquer natureza, garantidose aos brasileiros e aos estrangeiros residentes no país a inviolabilidade do direito à vida, à liberdade, à igualdade, à segurança e à propriedade, nos termos seguintes: [...] X - são invioláveis a intimidade, a vida privada, a honra e a imagem das pessoas, assegurado o direito a indenização pelo dano material ou moral decorrente de sua violação. (BRASIL, 1988).

Dispõe ainda o art. 227, do mesmo diploma:

É dever da família, da sociedade e do Estado assegurar à criança, ao adolescente e ao jovem, com absoluta prioridade, o direito à vida, à saúde, à alimentação, à educaçáo, ao lazer, à profissionalização, à cultura, à dignidade, ao respeito, à liberdade e à convivência familiar e comunitária, além de colocálos a salvo de toda forma de negligência, discriminação, exploração, violência, crueldade e opressão. (BRASIL, 1988).

Além disso, o Estatuto da Criança e do Adolescente (BRASIL, 1990), garante em seu art. 18, que "é dever de todos velar pela dignidade da criança e 
O fenômeno do bullying homofóbico nas instituições de ensino: o direito à igualdade sexual e o princípio da dignidade da pessoa humana

do adolescente, pondo-os a salvo de qualquer tratamento desumano, violento, aterrorizante, vexatório ou constrangedor".

Assim, observa-se que o fenômeno do bullying homofóbico é, uma violação a dignidade da pessoa humana, uma vez que coloca a vítima em situaçóes vexatórias e degradantes, transformando-a em mero "brinquedo", impedindo de exercer a autodeterminação.

De acordo com Miguel e Pereira (2008, p. 923),

A ideia de uma ética do cuidado nas relaçóes humanas implica numa concepção complexa de ser humano, de conhecimentos, de afetos, de reflexão sobre como afetamos e somos afetados em nossas trocas. Na multiplicidade de sentidos para o conceito de cuidado, acreditamos que a vida e o jogo das relaçôes só sobrevivem se forem cercados de atençấo e de desveio, assim como, acreditamos que o cuidado provoca preocupação e faz surgir o sentimento de responsabilidade. Talvez seja este sentimento de responsabilidade que faça com que se rompam as barreiras do silêncio e se denuncie uma situação de violência.

Dessa forma, cabe as instituiçóes de ensino como um espaço ideal para a socialização do saber e, consequentemente, como um lugar de gestâo do cuidado, envolver toda a comunidade educativa, pais, professores/as e funcionários/ as, em uma discussão sobre as questôes da violência. A constituição de uma ética do cuidado perpassa por um caminho que deve ser trilhado com muita compreensão e diálogo, sendo que os procedimentos educativos nesta perspectiva, com crianças, adolescentes, jovens e adultos poderão assim, firmar um desenvolvimento mais saudável.

Portanto, sendo a educação um direito fundamental garantido em lei, tanto no âmbito internacional como nacionalmente e para se construir uma sociedade democrática e livre de preconceitos, há de se garantir o acesso à educação, mas que esta se desenvolva como espaço de cidadania, liberdade e diversidade (PEREIRA; BAHIA, 2011), e caso não haja uma atitude contributiva do Poder Público, da sociedade e da própria educação, no sentido de resguardar e proteger a dignidade da pessoa humana acabar-se-á por legitimar a prática do bullying homofóbico.

Compreensôes críticas e reflexivas da dimensão do fenômeno do bullying homofóbico em todos os seus aspectos existenciais se faz imprescindíveis na atualidade. Liberdade, autonomia, proteção, saúde e, sobretudo, igualdade sexual e dignidade, são valores universais do ser humano. Ante tais compreensóes é que se vai construindo os saberes essenciais como fio condutor da vida, da educação em dignidade humana. 


\section{Considerações}

Sendo a violência uma das grandes questóes sociais a serem solucionadas pela humanidade, traz-nos um olhar sobre a compreensão deste fenômeno praticado contra crianças, adolescentes, jovens e adultos, proporcionando-nos um mergulho na identificação de fatores que movem esta violência social, em especial, na educação.

Como podemos perceber ao longo deste artigo, a violência ao ser praticada no âmbito educacional, chega a atingir um número significativo de discentes de todas as faixas etárias, evidenciando a necessidade de políticas públicas efetivas que visem um trabalho sistemático de qualidade no combate a esta problemática. Isto pode ser realizado através de campanhas nacionais de prevenção, capacitação de todos os profissionais das instituiçôes de ensino, com o intuito de formar alianças e parcerias dentro da própria rede de atendimento com o Poder Público.

Dentro do exposto até o momento, é válido reafirmar a problemática da homofobia em nossa sociedade, sendo esse, um dos últimos preconceitos ainda aceitos, ou pelo menos vivenciado de forma velada por aqueles que observam como expectadores, coadjuvantes das práticas de agressão e violência contra a comunidade LGBT mais especificamente, e de forma generalizada, a todo e qualquer ser humano que expresse e vivencie sua identidade de gênero e orientação sexual de forma diversa ao estereótipo considerado padrão.

A partir da realização do presente estudo, pôde-se perceber que enquanto o problema da violência nas instituiçóes de ensino - fenômeno do bullying homofóbico - não for devidamente compreendido, acabaremos legitimando sua prática e esqueceremos-nos de proteger, respeitar e promover o atributo maior do ser humano, sua dignidade. Mas, mais do que isso, é preciso desvelar essa prática como passível de recriminação e criminalização, para que se possa efetivamente combatê-la.

O bullying homofóbico é um problema social que vem fazendo, expressivamente, inúmeras vítimas - crianças, adolescentes, jovens e adultos em processo de formação - e não se restringindo a uma determinada classe social. E por se tratar da prática de comportamentos lesivos e destrutivos à saúde física e psíquica dos sujeitos, necessita de cuidados especiais, sendo imprescindível uma análise minuciosa e abrangente entre os campos da sociologia, psicologia, assistência social, e não somente do âmbito jurídico. Principalmente pela necessidade de trazer tal discussão para o espaço educacional, junto a sua comunidade, de forma a garantir a discussão e reflexão crítica do tema junto a todos/as, como maneira primeira de cessar com tal prática. Faz-se importante ressaltar que, em se tratando do ordenamento jurídico brasileiro, os princípios constitucionais consagrados possuem suma carga normativa, visando, desse 
O fenômeno do bullying homofóbico nas instituiçóes de ensino: o direito à igualdade sexual e o princípio da dignidade da pessoa humana

modo, o resguardo dos direitos e garantias individuais, entre elas a dignidade da pessoa humana.

A Constituição Brasileira de 1988 consagrou a dignidade da pessoa humana como fundamento estrutural da República Federativa do Brasil, sendo enxergado como o legítimo princípio fundamental de proteção dos direitos de todas as pessoas. O direito à igualdade sexual, como direitos humanos universais e o princípio da dignidade da pessoa humana, representa um importante componente constitucional, uma vez que é a diretriz a ser seguida, que inclusive legitima a ordem estatal. Logo, as ações do Poder Público devem estar pautadas na busca constante de proteger e promover o direito à igualdade sexual e a dignidade da pessoa humana, construindo mecanismo para o seu pleno exercício, para que então violências como as praticadas no bullying homofóbico não sejam tratadas como brincadeiras inocentes no processo de formaçáo de crianças, adolescentes, jovens e adultos.

Nessa perspectiva, Pereira (2013), afirma que o tema da sexualidade é complexo, pois nem todas as pessoas a entendem e vivenciam da mesma forma, e, abordar o tema pode ser ainda mais difícil e divergente. A autora também ressalta para o fato de que "[...] uma mudança de postura deve ocorrer nas instituiçóes escolares. Ainda existe uma grande confusão nos educandos sobre os aspectos relacionados à sexualidade humana, confusâo essa determinada pela falta de informação." (PEREIRA, 2012, p. 202), o que de fato, permite que as confusóes vivenciadas na adolescência pelos/as alunos/as sejam experienciadas na forma de preconceitos e atitudes de violência física e psicológica, como é o caso do bullying homofóbico.

Para tanto é fundamental que se quebre o silêncio que envolve a problemática do bullying homofóbico, silenciamento esse "[...] que se traduz também na omissão quando aparecem os casos de violência física ou verbal sofrida por estudantes que expressam sua diferença sexual e de gênero." (DINIS, 2011, p. 43), e que, compartilhado por professores/as que sentem receio de abordar o tema de forma intencional acabam por compactuar e, até certo ponto, garantir que essa prática permaneça a fazer vítimas.

Sendo as instituiçóes de ensino um dos lugares mais difíceis de expressar socialmente, principalmente por parte dos adolescentes, assumirem sua identidade de gênero e/ou orientação sexual é ainda mais complexo, e solitário. Caminho pelo qual, alunos/as enfrentam muitas vezes sozinhos e sem apoio, quando inseridos numa atmosfera de negação por parte da comunidade educacional, colocando os sujeitos em condição de vulnerabilidade, impossibilitando a vivência plena de sua condição humana, garantida pelo direito à igualdade sexual, e pelo princípio da dignidade da pessoa humana.

Afirma Dinis (2011, p.47) que: 
[...] essa ignorância sobre o tema, assim como a presunção assumida por professoras/es de que a escola só deva discutir assuntos universais, sendo somente a norma da heterossexualidade concebida como o natural e universal, exclui a sexualidade de estudantes LGBTTs e faz com que a diversidade sexual e de gênero seja um tema excluído do currículo, mesmo das aulas de educação sexual.

Diante do exposto, compreendemos que, sendo a prática do bullying homofóbico, muito presente nos espaços educativos como afirmamos anteriormente, é uma prática social e cultural, presente nas diferentes sociedades contemporâneas, e por se tratar ainda de um tema muito velado e negado, tem se propagado expressivamente. Assim, torna-se fundamental o fortalecimento de políticas públicas que possibilitem a vivência plena da sexualidade, garantindo o direito de uma educaçáo sexual que permita às crianças, adolescentes, jovens e adultos vivenciar seus corpos, prazeres, direitos sexuais, de forma emancipatória, assegurando o direito à igualdade sexual e ao direito a dignidade da pessoa humana.

\section{REFERÊNCIAS}

ALVES, C. F. O princípio constitucional da dignidade da pessoa humana: o enfoque da doutrina social da Igreja. Rio de Janeiro: Renovar, 2001.

ANTONIO, R. et al. Bullying homofóbico no contexto escolar em Portugal. Psicologia, Lisboa, v.26, n.1, p.17-32, 2012. Disponível em: <http://www.scielo.gpeari.mctes.pt/scielo. php?pid=S0874-20492012000100002\&script=sci_arttext> Acesso em: 29 set. 2014.

BRASIL. Lei no 8.069, de 13 de julho de 1990. Dispóe sobre o Estatuto da Criança e do Adolescente e dá outras providências. Diário Oficial [da] Uniáo, Brasília, 16 jul. 1990. Disponível em: <http://www.planalto.gov.br/ccivil_03/leis/18069.htm>. Acesso em: 29 set. 2014.

. Constituiçáo da República Federativa do Brasil de 1988, de 05 de outubro de 1988. Brasília, 1988. Disponível em: <http://www.planalto.gov.br/ccivil_03/Constituicao/ Constituicao.htm>. Acesso em: 29 set. 2014.

CALHAU, L. B. Bullying: o que você precisa saber: identificação, prevenção e repressão. 2.ed. Rio de Janeiro: Impetus, 2010.

DINIS, N. F. Homofobia e educação: quando a omissão também é signo de violência. Educar em Revista, Curitiba, n.39, p. 39-50, jan./abr. 2011. Disponível em: <http://www. scielo.br/pdf/er/n39/n39a04>. Acesso em: 29 set. 2014.

FANTE, C.; PEDRA, J. A. Bullying escolar: perguntas \& respostas. Porto Alegre: Artmed, 2008. 
O fenômeno do bullying homofóbico nas instituiçóes de ensino: o direito à igualdade sexual e o princípio da dignidade da pessoa humana

JUNQUEIRA, R. D. Homofobia: limites e possibilidades de um conceito em meio a disputas. Disponível em: <http://www.fafich.ufmg.br/educacaosemhomofobia/TextosSite/ Homofobialimitesepossibilidadesdeumconceitoemmeioadisputas.pdf $>$. Acesso em: 08 jul. 2015.

LOPES NETO, A. A. Bullying: saber identificar e como prevenir. São Paulo: Brasiliense, 2011.

LOURO, G. L. Gênero, sexualidade e educação: uma perspectiva pós-estruturalista. Petrópolis: Vozes, 1997.

MIDDELTON-MOZ, J.; ZAWADSKI, M. L. Bullying: estratégias de sobrevivência para crianças e adultos. Tradução de Roberto Cataldo Costa. Porto Alegre: Artmed, 2007.

MIGUEL, D.; PEREIRA, G. A escola, ética do cuidado e a questáo da violência doméstica: educação para a saúde no século XXI. Portugal: Universidade de Évora, 2008.

MORAES, A. de. Direito constitucional. 20.ed. São Paulo: Atlas, 2006.

OLIVEIRA, A. Curso de direitos humanos. Rio de Janeiro: Forense, 2000.

ORGANIZAÇÃO DAS NAÇÓESS UNIDAS [ONU]. Declaraçáo Universal dos Direitos Humanos: adotada e proclamada pela resolução 217 A (III) da Assembléia Geral das Naçóes Unidas em 10 de dezembro de 1948. Brasília, 1998. Disponível em: <http://unesdoc.unesco. org/images/0013/001394/139423por.pdf>. Acesso em: 26 set. 2014.

PEREIRA, G. R. Educaçáo sexual sem fronteiras: uma proposta de formação a distância para professores do Brasil, da Argentina, de Portugal, da Espanha e de Moçambique. In: PEREIRA, G. R.; RABELO, A.; REIS, M. A. (Org.). Formação docente em gênero e sexualidade: entrelaçando teorias, políticas e práticas. Petrópolis, RJ: Ed. da FAPERJ, 2013. p.195-210.

Mitos e tabus: perspectivas de mudança relacionadas a sexualidade humana. In: REIS, M. A. de S.; ALEVATO, H. (Org.). Nexus \& sexus: perspectivas instituintes. Petrópolis, RJ: Ed. da FAPERJ, 2012. p. 197-208.

PEREIRA, G. R.; BAHIA, A. Direito fundamental à educação, diversidade e homofobia na escola: desafios à construção de um ambiente de aprendizado livre, plural e democrático. Educar em Revista, Curitiba, v. 39, p. 51-72, 2011.

SARLET, I. W. Dignidade da pessoa humana e direitos fundamentais na Constituiçáo Federal de 1988. 4.ed. rev. atual. Porto Alegre: Livraria do Advogado, 2006.

SILVA, A. B. B. Bullying: mentes perigosas nas escolas. Rio de Janeiro: Objetiva, 2010.

SILVA, J. A. da. Curso de direito constitucional positivo. 35.ed. São Paulo: Malheiros, 2012.

SILVEIRA, G. P. et al. Reflexóes sobre o Bullying e o Cyberbullying: o papel do diretor de escola na prevenção deste fenômeno. Aveiro: Universidade de Aveiro, 2011. 
TEIXEIRA, G. Manual antibullying: para alunos, pais e professores. Rio de Janeiro: BestSeller, 2011.

WARNER, M. Fear of a queer planet: queer politics and social theory. Minneapolis: University of Minnesota Press, 1993.

WORLD ASSOCIATION FOR SEXUAL HEALTH [WAS]. Declaraçáo dos direitos sexuais. Hong-Kong, 1999. Disponível em: <http://www.worldsexology.org/wp-content/ uploads/2013/08/DSR-Portugese.pdf>. Acesso em: 26 set. 2014. 
O fenômeno do bullying homofóbico nas instituiçóes de ensino: o direito à igualdade sexual e o princípio da dignidade da pessoa humana

\section{Resumo}

O fenômeno do bullying homofóbico nas instituiçôes de ensino: o direito à igualdade sexual e o princípio da dignidade da pessoa humana

O presente artigo propóe compreender o fenômeno do bullying homofóbico, com o intuito de verificar qual o respaldo desta problemática no direito à igualdade sexual e no princípio da dignidade da pessoa humana. Para tanto, estudou-se as características gerais do fenômeno do bullying homofóbico, trazendo conceituaçáo, especificidades e pressupostos dessa violência social que é um dos temas mais polêmicos da atualidade. Abordou-se, por derradeiro, uma análise sobre um dos Direitos Sexuais, entendidos como Direitos Humanos fundamentais e universais - o direito à igualdade sexual e um dos fundamentos basilares da Constituiçáo Federal do Brasil, a dignidade da pessoa humana. Assim, buscou-se demonstrar as consequências que a prática do bullying homofóbico traz à humanidade, enfatizando para a importância da conscientização desta problemática no desenvolvimento saudável do ser humano, com a liberdade das discriminaçóes, independentemente de qualquer diferença, sexo, gênero, orientação sexual, geracional, etnia-racial, classe social, religiâo, deficiências, entre outras (Was, 2014). Procurou-se, para as referidas análises, utilizar-se do mais recente material bibliográfico. Por fim, destaca-se que o fenômeno do bullying homofóbico necessita ser compreendido, senão acabar-se-á legitimando sua prática e, consequentemente, esquecerse-á de proteger à condição humana.

Palavras-chave: Educação. Bullying homofóbico. Direito à igualdade sexual. Dignidade da pessoa humana.

\section{Abstract}

The phenomenon of homophobic bullying in education institutions: the right to sexual equality and the principle of human dignity

This paper seeks to understand the phenomenon of homophobic bullying, in order to find what the support of this issue on the right to gender equality and the principle of human dignity. For this, we studied the general characteristics of the homophobic bullying phenomenon, bringing concepts, characteristics and assumptions of this social violence that is one of the most controversial topics of the day. Approached to finally, an analysis of one of Sexual Rights, understood as fundamental and universal human rights - the right to sexual equality and one of the basic foundations of the Federal Constitution of Brazil, the dignity of the human person. Thus, it sought to demonstrate the consequences of the practice of homophobic bullying brings to mankind, emphasizing the importance of awareness of this issue in the healthy development of the human being with freedom of discrimination, regardless of any differences, sex, gender, sexual orientation, generational, ethnic-racial, social class, religion, disability, among others (WAS, 2014). An attempt was made to this analyzes using the very latest bibliographic material. Finally, there is the phenomenon of homophobic bullying needs to be understood, if not eventually will be legitimizing their practice and consequently will forget to protect the human condition.

Keywords: Education. Homophobic bullying. Right to sexual equality. Dignity of the human person. 